\title{
Moral dimension of scientific knowledge in the conditions of formation of a new industrial society
}

\author{
Elena Shetulova* and Marina Zaladina \\ Nizhny Novgorod State Technical University n. a. R.E. Alekseev, 603950, Nizhny Novgorod, Russia
}

\begin{abstract}
The purpose of this article is to research the problem of the relationship between science and moral in the new industrial society. The main result of the research can be expressed in a number of the following theses. The functioning and interaction of science and moral depends on the existing social conditions. Accordingly, the relationship between science and moral must be considered specifically historically. In the early stages of becoming a social institution, modern science was an ethically neutral form of culture. Approximately from the late 19th - early 20th centuries, the situation gradually changed in the direction of increasing the moral component of scientific knowledge. The emerging industrial society of the second generation predetermines the dominance of the significance of moral issues in all spheres, including the sphere of science. The reason for such dominance is the inability to control technological processes completely, as well as the ever-increasing interference with the surrounding nature and human nature.
\end{abstract}

\section{Introduction}

The problems of modernity (Fedotova, Kolpakov, Fedotova; Ivleva, Kurmeleva, Rudanovskaya; Shulgin, Zinkina, Andreev), new technological revolution (Golichenko; Knyaginin, Idrisov, Kuzmina, Rozhkova, Sultanov; Akaev, Rudskoi, Sarygulov, Sokolov), scientific knowledge (Mamchur; Fedotova, Yakovleva; Stepin; Markova; Antonovsky), ethics, including the ethics of science (Agazzi; Guseinov; Apresyan) are peculiar trends of modern philosophical research [1-16]. Each of these discourses includes many aspects and dimensions, including their complex combining. One of the most important is the relationship between science and moral in the conditions of the modern world. Morality and science are two forms of culture, which in different ways reflect the world with the processes taking place in it and with the phenomena of reality. Two main positions formed on the problem of the relationship between science and morality. According to the first position, the relationship between science and moral is practically absent, science is ethically neutral, and scientists should not bear moral responsibility for their discoveries.

\footnotetext{
* Corresponding author: shetulowa@yandex.ru
} 
According to the second, science and moral actively interact and mutually influence each other. In fact, both are correct. But we must take into account the fact that science and moral function and interact in different ways, depending on the respective historical conditions. Modernity is characterized by moving towards a new industrial society of the second generation. In this society, the uncontrollability of the techno sphere, the increasing degree of interference into nature, into human corporeality predetermine the need for a new appeal to the analysis of the relationship between science and morality.

\section{Research method}

An adequate research of the relationship between science and moral implies compliance with the following procedures and methods of analysis. Moral and science are two forms of culture and two spheres of social life, that's why consideration of them includes their understanding as systems characterized by integrativity.

Society, as integrity, morality and science, as its subsystems, is constantly evolving, which determines the need for their cognition not only in statics, but also in dynamics. Modern morality is not identical to the morality of the industrial society of the XIX century, not to mention the earlier eras. Modern science, based on the principles of global evolutionism and anthropic, is significantly different from the science of the XVIII century. It is wrong to ignore this fact in the research of the relationship between science and morality.

Morality and science are independent forms of culture. However, it is unacceptable to deny the existence of a connection between them. Their apparent mutual indispensability at the same time means their complementarities as being different ways of people assimilating reality. Science is a universal way of this development, and morality has a cultural "dimension" of a particular society.

\section{Moral in its relation to science}

Science and moral are such ways of understanding and mastering reality, which are interrelated and mutually necessary by virtue of their specificity. Moral is an appraisalimperative way that regulates the behavior of people within the confrontation of good and evil, due and existing. Science is the theoretical assimilation of the world, knowledge, seeking for the truth, the elimination of errors. About the generality and specificity of science and moral O.G. Drobnitsky wrote: «morality, like scientific thinking, is a definite way for a person to understand his historical being. If this is not theoretical knowledge, then at least a certain idea of reality, expressing its objective laws in a special language» [17].

Ideas about the relationship of science and moral arose already at the time of their inception. This is evidenced by the aphorism of one of the seven ancient sages: "Know yourself, and you will know the gods and the Universe." And throughout the entire history, parallels were constantly drawn between the "starry sky above me" and the "moral law in me."

Moral, along with other kinds of spiritual culture stimulates the process of scientific knowledge. This aspect was emphasized by A. Einstein in an interview with J. Murphy and the American physicist J. Sullivan: “... I consider it important to share the most diverse ways to comprehend the truth. By this I mean that our moral inclinations and tastes, our sense of beauty and religious instincts contribute to helping our mental activity to come to the highest achievements" [18]. 
But was there really a significant effect of morality on scientific knowledge in the early stages of its development, outside the context of the actual mental stimulation? We believe that before the initial periods of the formation of science as a social institution, i.e. until the mid-twentieth century, this impact was almost nonexistent.

As shown by B.G. Yudin, the social institute of science, having begun its formation in the XVI-XVII centuries, went through several stages of development. The first was in the XVI-XVII centuries, the second - in the XVIII - the first half of the XIX. At this time, the social institute of science was only taking shape, beginning to perform a number of important public functions. The key stage is the third stage - from the middle of the XIX to the beginning of the twentieth century.

The following points are of fundamental importance. Primarily it is the new understanding of nature: science is not only a theory, representing the phenomenon and revealing its essence. Science is evaluated in terms of economic and technological efficiency. Science goes beyond the walls of the laboratory, its results are used in industrial production, are transformed into a kind of market product [19]. Secondly, science ceases to be an amateur occupation and becomes a profession. These processes had a number of important consequences, including the formation and expansion of the installation on the normative value neutrality of science.

But when in the mid-twentieth century, thanks to commercialization and practicality, science began to constantly increase its influence on society, an unsatisfactory value-neutral approach was revealed. The importance of ethical regulation of scientific research, both within the scientific community and from society, has become obvious.

\section{Ethical regulation of science as a social and epistemological problem}

The ethical regulation of science from within is conceptualized in the scientific ethos itself, one of the most popular versions of which was proposed by R. Merton. According to his concept, the norms of science express themselves in the form of four fundamental principles: universalism, community, disinterest and organized skepticism [20]. Despite some criticism, this concept remains generally accepted.

The ethical regulation of science from the outside is a somewhat more complicated problem. In solving it, firstly, it is necessary to avoid excessive abstractness, which is often characteristic of considering moral issues. Secondly, the solution of this question requires taking into account the evolution, both of society as a whole and of science and moral as specific forms of culture.

According to the authors, in order to avoid the abstract nature of the question about the relationship between science and morality, it is imperative to observe two conditions. The first is the need to link the solution of this problem with social tasks [21]. We agree with the opinion of R.G. Apresyan that "the basis on the basis of which can be deployed ... ethical programs implies a social and communicative infrastructure that is possible only in a democratically organized environment." Moreover, this environment can be different "not only at the public level, but also at the communitarian and at the group level" [22].

There is an objective public need to study modern moral processes in all their inconsistencies and complexity, including those that take place in the scientific field. The social tasks of modernity in the study of moral problems in the field of science are determined by the status of science in the "knowledge society" [23].

In this society, there is concern about the possible negative consequences of the introduction of the results of scientific discoveries, the contradiction between the desire of civil society to participate in social decision-making and the increasing anti-Scientist sentiment. Significantly help in resolving the contradiction can measures developed by 
scientists-ethics: the formation of new scientific ethics, the establishment of interdisciplinary commissions on ethics, the creation of codes of professional ethics in various fields of knowledge [19].

The second condition is to take into account the epistemological components in the content of the problem of the relationship between science and morality [21]. Note the contradictions in the development of science and its relative imperfection at each stage of development [24]. This also includes the processes of integration of subjects and methods of individual disciplines in today's science. This means not only a change in scientific paradigms, but also the need to synthesize various areas of knowledge. Finally, the growth processes of the heuristic modern moral programs. Not dogmatism, not leading actions to certain declared requirements, but searching for the justification of the requirements themselves, up to the question of the criteria for the truth of moral doctrines. In modern society, neither corporate, nor class, nor purely religious moral codes can be considered satisfactory.

\section{Transformation of moral requirements for science in conditions of modernity: global and russian context}

The requirement of moral responsibility of scientists for the results of their research was strengthened by the scientific and technical revolution that began in the mid-twentieth century. Its global character, the tremendous impact on the entire social system extended the sphere of moral evaluation of scientific activities till a global scale. One of the social consequences of the scientific and technological revolution has become the constant renewal and change of the technical and production base of society.

If you look at the problem from the point of view of the development of production and the economic system, now, according to a number of researchers, a second-generation industrial society is gradually emerging [25]. A comprehensive, systematic review shows the presence of both positive and negative aspects of its development.

According to S.D. Bodrunov, the positive aspects include the reduction of material costs in the production cycle, an increase in its scientific component. Also positive should be considered a change in the position of a person in terms of his gradual ousting from production, with an increase in the overall ability to meet needs [25]. There are also negative trends, the main of which is the threat of a civilizational crisis, which has both a social-ecological and an anthropological component. Socio-ecological is a constant increase in production load on nature, and often in favor of not natural, but artificially created needs. The anthropological component is in the emergence of opportunities for intervention not only in the natural environment, but in human nature [25]. The solution to the problem should be sought in the moral sphere, in the transition from the zoological desire to absorb more and more material resources to the rational self-restriction of human needs [25].

In the authors' opinion, the emergence of the second generation of industrial society actualizes the issue of the professional morality of scientists as subjects of the historical movement of the modern socio-economic system.

The main moral requirement to scientist is objectivity. In this requirement, the field of scientific methodology and the sphere of morality coincide. Strict observance of objectivity is a marker of professional readiness of a scientist. From the point of view of methodology, objectivity contains requirements of factuality, impartiality, validity, and criticality. However, adherence to objectivity is not enough if we are talking about the professional ethics of a scientist. He must also be in harmony with his conscience. In a situation of moral choice, a scientist should always remain on the side of truth, neglecting well-being, showing civil courage and dedication. 
However, there are objective obstacles to the successful functioning of ethical codes in Russian universities. First of all, this is the low level of their administrative and financial independence at the present time. This is manifested, as R.G. Apresyan writes, in "petty accountability to different levels of government ... and in limiting the competence of universities in shaping the structure of the educational program and determining its content. Every now and then, universities are hostages of conflicting tasks set by the federal and regional authorities" [22]. But the ethics of science can function only based on professional communities that have a certain degree of autonomy.

The second factor is the commercialization of education, when the results of scientific knowledge are perceived as a commodity, and minimization of expenses and, accordingly, profit maximization are seen as criteria for the efficiency of knowledge production. In this case, knowledge invaluable (from the point of view of morality) begins to be assessed according to the laws of the market, in accordance with the balance of supply and demand. Scientists acquire the status of either competitors, or means at the expense of which one can make a profit, which contradicts the Kant's categorical imperative, which calls people to see not so much the means to achieve certain goals, as the goals themselves.

The system of values with the main reference point in the form of material gain inevitably deforms the relationship of a scientist with his colleagues and his entire moral world. "If people lose the moral foundations of their existence, then no expected material well-being will save society from destruction. The standards of market relations gain a total character, are reproduced in the moral sphere, bring to life specific personality characteristics aimed exclusively at consumerism" [26].

The third factor hindering the proper functioning of ethical codes in universities is the teacher unions that practically do not work on this issue and do not provide enough free conditions for the scientific creativity of the teaching staff.

\section{Conclusion}

Consideration of the ethical regulation of science allowed us to distinguish two of its aspects. Firstly, it is the regulation of science from within, conceptualized in the ethics of science. Secondly, it is the regulation from the outside. The study in the second plan is rather complicated because of the prevalence of abstractness in the formulation and resolution of moral problems, and because of ignoring the evolutionary changes of society as an integrity, and science and morality as forms of culture. The proposed solution to overcome these difficulties is to link the solution of the problem of the relationship between morality and science with social problems, to reveal the impact of an evolving society on the moral regulation of science, the development of scientists' ethics, and also to take into account the epistemological component of the problem.

\section{Prospects and directions for future research}

The scientific and technological revolution at the turn of the second and third decades of the 21 st century gave rise to the trends of the emergence of a second generation industrial society. In view of this, there was an increase in the possibilities of intervention both in the natural environment and in human nature, in its heredity, in questions of life and death (euthanasia), in the common fate of humanity as a species (the use of thermonuclear energy). This actualizes the question of the moral responsibility of scientists for the use of the achievements of science. Its further development is in the trend of philosophical research. However, the scientists themselves must also know and understand the basic rules and requirements of professional ethics. Moral education is necessary, impossible without 
teaching ethics courses in the system of higher education, especially in the training of graduate students. This requires the implementation of research on the ethics of science in training courses and pedagogical technologies, which, in turn, is unrealizable without preliminary theoretical understanding.

\section{References}

1. V.G. Fedotova, V.A. Kolpakov, N.N. Fedotova, Voprosy Filosofii, 10 3-12 (2013)

2. M.L. Ivleva, E.M. Kurmeleva, S.V. Rudanovskaya, Voprosy Filosofii, 4 191-195 (2018)

3. S. Shulgin, J. Zinkina, A. Andreev, Social Evolution and History, 1(18) 127-138 (2019)

4. O.G. Golichenko, Innovations, 3(137) 12-22 (2010)

5. V.N. Knyaginin, G.I. Idrisov, A.S. Kuzmina, E.S. Rozhkova, D.K. Sultanov, New technological revolution: challenges and opportunities for Russia. Expert-analytical report (Center for strategic research, Moscow, 2017)

6. A. Akaev, A. Rudskoi, A. Sarygulov, V. Sokolov, Social Evolution and History, 1(18) 67-93 (2019)

7. E. Mamchur, Russian Studies in Philosophy, 3(49) 7-23 (2010)

8. V.G. Fedotova, A.F. Yakovleva, Russian Studies in Philosophy, 3(53) 231-241 (2015)

9. V.S. Stepin, Russian Studies in Philosophy, 2(53) 159-167 (2015)

10. V.S. Stepin, Russian Studies in Philosophy, 2(53) 168-180 (2015)

11. L.A. Markova, Russian Studies in Philosophy, 1(55) 26-36 (2017)

12. A.Yu. Antonovskiy, Voprosy Filosofii, 12 97-100 (2018)

13. E. Agazzi, Voprosy Filosofii, 9 93-104 (2009)

14. A. Guseinov, Russian Studies in Philosophy, 3(52) 18-38 (2013)

15. A. Guseinov, Russian Studies in Philosophy, 3(52) 39-55 (2013)

16. R.G. Apresyan, Russian Studies in Philosophy, 6(54) 456-470 (2016)

17. O.G. Drobnitsky, Moral philosophy (Gardariki, Moscow, 2002)

18. A. Einstein, How to change the world for the better (Algoritm, Moscow, 2013)

19. B.G. Yudin, Voprosy Filosofii, 8 45-57 (2010)

20. R.K. Merton, Social Theory and Social Structure (Free press, New York, 1957)

21. M.V. Zaladina, News of the Academy of Engineering Sciences of the Russian Federation n. a. A.M. Prokhorov. Philosophy of the science, technics and technology (Moscow and Nizhny Novgorod, Talam, 2005) 62-66

22. R.G. Apresyan, Statement of applied ethics, Research Institute PE, Tyumen, 52, 9-18 (2018).

23. P.F. Drucker, The Age of Discontinuity: Guidelines to our changing society ( Harper \& Row, New York,1969)

24. H. Rickert, Science of nature and cultural science. (Respublika, Moscow, 1998)

25. S.D. Bodrunov, Noonomics (Kulturnaya revolutsiya, Moscow, Saint Petersburg and London, 2018)

26. M.V. Zaladina, E.D. Shetulova, Bulletin of the Vyatka State University, 5, 6-9 (2017) 